\title{
COOPERATIVISMO E PEQUENA PRODUÇÃO FAMILIAR MODERNIZADA
}

(OCASODOPERIMETRO IRRIGADO DE SÃO GONÇALO-PB)

Paulo Ortiz Rocha de Aragão ${ }^{l}$

Claudia Nascimento Queiroz ${ }^{2}$

\section{INTRODUCÃO}

A partir da segunda metade dos anos 60 foram lançadas as bases institucionais de um projeto de modernização para a agricultura brasileira. Em sua essência, este projeto, pretendia alterar a estrutura técnica da produção agrícola, equiparando-a com a dos países desenvolvidos, em dois aspectos fundamentais: rentabilidade e produtividade. As excelentes oportunidades de exportações de produtos agrícolas brasileiros para $o$ mercado mundial contribuíram de forma significativa para o processo de modernização. Em conseqüência da modemização, o perfil do setor agrícola nacional passou por importantes modificaçôes em sua base técnica. ${ }^{3}$

Nesse sentido, foram dados importantes estímulos e subsídios à produção industrial, com vistas à intensificação do processo de industrialização em curso, fazendo-o avançar inclusive, sobre o meio rural. Surgiram

${ }^{1}$ Ph.D em Sociologia, Professor Titular do Departamento de Economia e Finanças, Universidade Federal da Paraíba.

${ }^{2}$ Mestre em Economia, Professora Assistente do Departamento de Economia, Universidade Federal de Sergipe.

${ }^{3}$ Para uma discussão mais detalhada das questões aqui sintetizadas, consulte-se Martine \& Beskow (1987, 19-41). 
complexos agroindustriais com o capital industrial e financeiro encontrando novas formas de realização dentro da agricultura, que passou a assumir um importante papel, não somente como produtora de matérias-primas e alimentos, mas também como mercado para o parque industrial, em termos de máquinas e insumos agrícolas.

Foi nesse periodo que a irrigação passou a ser vista como importante estratégia de modernização para o setor agricola, em especial, nas áreas semi-áridas do Nordeste do pais. Com o advento do Programa de Integração Nacional (PIN), em 1970, e seguindo a concepção do Banco Mundial de "erradicar a pobreza rural e fortalecer as economias das zonas semi-áridas contra os efeitos das secas ou estiagens prolongadas", o Estado criou um programa de irrigação especifico para a região Nordeste, com vistas à implantação de uma economia de mercado no setor agrícola regional (BNB/ETENE 1985, 22).

O Programa de Irrigação do Nordeste seria executado na região pelo Departamento Nacional de Obras Contra as Secas (DNOCS) e pela Companhia de Desenvolvimento do Vale do São Francisco (CODEVASF). Em ambos os casos a ênfase compreendia, basicamente, a criação dos Projetos de Irrigação, também denominados Perímetros de Irrigação. Enquanto que a CODEVASF teria como objetivo expandir as áreas irrigadas que estivessem conjugadas às agroindústrias e atrair empresários para o vale do rio São Francisco, ao DNOCS caberia atuar especificamente com a chamada irrigação pública em projetos de colonização, com base no assentamento familiar e na organização dos produtores em cooperativas (MARA/SENIR, 1990, 14).

No caso dos Projetos Públicos, que constituem nosso objeto de estudo, verifica-se explicitamente nos objetivos da política de irrigação, a criação de uma "classe média rural" e a constituição de um determinado tipo de agricultor, o colono irrigante, que deveria passar a adotar atitudes e comportamentos diferentes daqueles tradicionalmente caracteristicos de um pequeno produtor familiar, dedicado à prática de uma agricultura de sequeiro, apresentando, em geral, baixos indices de tecnificação e de produtividade (BNB/ETENE 1985, 37; MARA/SENIR 1990, 41). 
Para adaptar agricultores com tais características ao padrão agrário de produção e de comercialização pretendido, alguns pressupostos foram elaborados. Inicialmente partia-se da premissa de que esses produtores passariam a contar com todas as condiçôes necessárias ao seu maior envolvimento com os instrumentos de modernização, através de uma política agrícola complementar em matéria de crédito, pesquisa, assistência técnica e preços adequados (MARA/SENIR 1990, 40).

Além disso, sendo os perímetros públicos espaços organizados pelo Estado para viabilizar uma produção capitalista, pressupunha-se que as suas ações deveriam respaldar, ou mesmo possibilitar o aprofundamento de relações capitalistas de produção. Por conseguinte e na mesma linha, inferia-se que a tecnificação desses produtores implicaria na sua transformação em pequenos empresários capitalistas (ibid 41).

Com base nesses mesmos pressupostos, foram elaborados os chamados estudos de viabilidade sócio-econômica dos projetos de irrigação (ibid 40). Nesses estudos, a expectativa criada era de que os beneficiários dos referidos projetos estivessem conjuntamente integrados ao padrão agrário de produção e de comercialização desejado. Passando-se a exigir, seja de diferentes perímetros, seja de colonos de um mesmo perímetro, respostas econômicas análogas em termos de produtividade/rentabilidade. A lógica dessas análises, por estar atrelada à mesma lógica de concepção dos projetos, aponta na direção de verificar se os colonos irrigantes estão sendo capazes de proporcionar o tipo de resposta econômica esperada, capaz de justificar o volume de investimentos públicos, realizado pelo Estado, nos projetos de irrigação.

Quando isso não ocorre, começa a se divulgar a idéia de que a irrigação pública é inviável, não se justificando social e economicamente. Isso ocorre, em grande medida, pelo fato das análises definidoras da eficácia e da eficiência do empreendimento, tomarem como referencial parâmetros convencionais (tais como relação beneficio-custo, taxa interna de retorno, estimativa de custos, entre outros), que, por sua própria natureza economicista, enfatiza aspectos estritamente quantitativos, sem se preocupar muito com as mudanças sociais e políticas que possam estar sendo viabilizadas nos Perímetros de Irrigação. Não se pretende dizer com isso que a obtenção de resultados econômicos não seja importante. Ao 
contrário, achamos que eles são importantes. Ocorre que ganhos nesse sentido fazem parte de um processo de transformação social mais amplo, cuja maturação não é tão rápida quanto tem sido desejada e as críticas condições de pobreza do Nordeste rural exigem.

Desse modo, a ausência de resultados consoantes com as metas propostas cxpõem, freqüentemente, os projetos de irrigação pública a constrangimentos que, cada vez mais, só dificultam o alcance dos objetivos programados. O mais problemático é que a obtenção de um resultado econômico, em um perímetro público, aquém do que é esperado dos referidos projetos, não é atribuída a uma inadequação institucional mais geral, ou à não implementação das políticas agrícolas, adequadas ao desenvolvimento da irrigação, como era prevista. A praxe tem sido atribuir o não cumprimento de metas e objetivos à falta de racionalidade econômica e a um fraco desempenho dos colonos/irrigantes, que passam a ser considerados como incapazes de adotar atitudes empresariais e por conseguinte, de dar conta de um empreendimento do tipo capitalista.

Entende-se que esses estudos induzem a um tipo de avaliação simplificadora de um complexo processo de transformação / modemização das relações sociais no campo brasileiro, reduzindo-o a uma clássica abordagem em termos de diferenciação social, por desconsiderar as múltiplas variações e possibilidades de inserção da produção familiar no processo de acumulação capitalista quando esta é submetida a estratégias modernizantes. Esse processo, assim como a própria sociedade capitalista, é também repleto de contradições, de ambigüidades e mesmo de conseqüências não vislumbradas. E seriam justamente nos espaços deixados em aberto por esses aspectos, que poderiam surgir alternativas que efetivamente representassem mudanças importantes em curso.

A criação dos perímetros de irrigação não é um acontecimento isolado, devendo ser situado no contexto mais amplo do movimento geral de expansão da sociedade capitalista em seu conjunto e, em particular, no contexto das comunidades envolvidas. Consideramos, por isso, que mais objetivo do que condenar esses projetos, seria tentar analisá-los sob uma ótica que contemplasse sua lógica e dinâmica internas, em vez de, simplesmente, avaliar seus resultados à luz de um modelo pré-concebido. Nessa perspectiva, se faz necessário reexaminar a estratégia oficial de 
modernização de pequenos produtores do Nordeste semi-árido, mediante a sua instalação em projetos de irrigação, buscando apreender o seu significado e as suas implicações sociais sobre o grupo de beneficiários envolvidos.

\section{METODOLOGIA E PROCEDIMENTO DA PESQUISA}

Este estudo teve como objeto o processo de transformações sociais em curso em um perímetro público de irrigação. Neste contexto, o objetivo do trabalho foi o de verificar a ocorrência de uma compatibilidade entre as ações declaradas de melhoria do padrão de vida desses produtores: e os resultados efetivamente encontrados, em uma experiência concreta. A complexidade e diversidade de situações concretas que envolvem a temática em questão, impôs, portanto, uma observação ao nível do particular. 0 caso concreto estudado foi o Perímetro Irrigado de São Gonçalo, criado em 1973, e localizado no município de Sousa, semi-árido paraibano, distando $440 \mathrm{~km}$ da capital do estado. A escolha deste perímetro deriva da circunstância de ser este um projeto com duas décadas de implantação e que, possivelmente, reúne muitas características de uma experiência já consolidada, mostrando-se, portanto, como um bom exemplo para a análise pretendida.

Para uma melhor compreensão do referido processo, concentramos nossa atenção em um estudo de caso. Se por um lado, esta estratégia de investigação limita as possibilidades de generalização dos resultados obtidos, por outro lado, permite o aprofundamento da observação empreendida. Procurou-se portanto, nos limites deste trabalho, analisar o conjunto das transformações sociais vivenciadas pelos pequenos produtores residentes no perímetro irrigado, sob uma ótica que contemplasse as suas expectativas e que indicasse o significado que essas mudanças representaram em suas vidas. Neste contexto empírico, procurou-se compreender e analisar como os colonos/irrigantes pensam as mudanças ocorridas em suas vidas, ao longo do tempo de sua inserção em projeto público de irrigação. De que modo, e até que ponto, essas mudanças têm contribuído para alterar as condições de manutenção / 
reprodução destes produtores e para thes proporcionar uma qualidade de vida mais digna?

Em meio a questionamentos como esses, os seguintes aspectos foram abordados de modo mais específico:

(a) Expectativas dos colonos/irrigantes mediante a sua inserção em um projeto de irrigação;

(b) Transformações mais importantes ocorridas no processo de produção e de comercialização dos produtores à medida em que vai se intensificando as suas relações com o mercado;

(c) Principais dificuldades de expansão da agricultura irrigada no âmbito de um projeto público.

$\mathrm{Na}$ decisão de estudar a experiência vivenciada por produtores de um perímetro de irrigação, pesou ainda a intenção de poder trazer alguma contribuição à tarefa de compreensão do processo de modemização / transformação imposto ao setor agrícola brasileiro, a partir dos anos 60 , no contexto mais amplo das mudanças ocorridas, que incluem mudanças nas relações de trabalho. Partindo de uma perspectiva comparativa das condições anteriores de manutenção e de reprodução dos produtores em relação às condições atualmente vividas no Projeto, foram realizadas entrevistas e aplicados questionários com os colonos/irrigantes. Foram entrevistados ainda, o pessoal técnico-administrativo do DNOCS e da Cooperativa dos Irrigantes.

A população analisada está distribuída entre três núcleos habitacionais (ou agrovilas), os quais foram denominados de acordo com a ordem numérica em que a sua infra-estrutura ia sendo concluída, a ponto de permitir o assentamento das primeiras familias selecionadas. Atualmente os três núcleos apresentam respectivamente 101, 169 e 156 familias. Foram aplicados questionários entre os meses de janeiro e fevereiro de 1993 sobre uma amostra de $19,7 \%$ de um total de 426 produtores que compõem o universo da pesquisa. A participação relativa dos produtores de cada núcleo na amostra é proporcional ao número de colonos residentes por núcleo residencial. Foram entrevistados 84 colonos, sendo 24 no núcleo I, 30 no núcleo II e 29 no núcleo III. 
Realizamos, ainda, consulta e análise da bibliografia disponível sobre a Política de Irrigação, especificamente dirigida para a região Nordeste, dando-se ênfase à estratégia adotada pelo DNOCS, uma vez que este foi o órgão responsável pela implantação do referido Projeto. Ficando destacados como elementos significativos desse processo: mudanças da base técnica da produção rural, a consolidação de um sistema nacional de crédito e o seu caráter desigual e excludente no que se refere a produtos, regiốes econômicas e grupos sociais.

\section{RESULTADOS}

$\mathrm{Da}$ análise da situação atual dos produtores residentes no perímetro irrigado de São Gonçalo, constatamos uma redefinição completa do processo produtivo que pode ser verificada sob diversas formas. A utilização de novas técnicas, bem como o acesso aos instrumentos de políica agrícola, permite afirmar a ocorrência de um processo de tecnificação entre os produtores analisados, embora esta não esteja se dando no mesmo ritmo para todas as fases de cultivo e para todas as unidades produtivas. Mudanças qualitativamente positivas em termos de condição financeira, aumento de produção, maiores possibilidades de escolaridade para os filhos, aumento do padrão de consumo familiar, também puderam ser constatadas, além de outros aspectos trazidos para ilustrar esta situação. Em virtude das limitações de espaço nos concentraremos nos aspectos relacionado com a produção agricola do perímetro e na evolução da cooperativa.

\section{A PRODUÇÃO AGRÍCOLA DO PERÍMETRO}

Durante os primeiros anos de operação dos perimetros públicos: de irrigação, havia um limitado controle dos produtores sobre o processo produtivo. A definição dos sistemas de produção foi uma das imposições do DNOCS. Seguindo o que havia sido previamente definido pelo planejamento estatal, muitas vezes foram introduzidas culturas em lotes agrícola que não eram apropriadas para o tipo de terreno utilizado 
Somentc o cultivo de produtos não-tradicional e de alto valor adicionado por hectare permitiria rentabilizar os projetos de irrigação. No discurso oficial, cste tipo de direcionamento agricola aparece, portanto, como uma tentativa de organizar a atividade agricola, adequando-a aos padrões de uma agricultura comercial modemizada, que permita garantir uma margem de lucro suficiente para rentabilizar os projetos face aos custos fixos da agricultura irrigada.

Dentre as culturas apontadas como as únicas que dariam vantagens em termos econômicos às áreas irrigadas, incluíam-se frutas e hortaliças, em especial uva, melão, cebola, batata, tomate e alfafa. E previa-se, por isso, que a produção de culturas como o algodão, o arroz e o feijão, culturas tidas como tradicionais, seriam comparativamente pequena nos perimetros de irrigação. 0 perímetro de São Gonçalo não foi uma cxceção à regra geral. Sendo a atividade agricola dirigida para a comercialização, não havia na fase de implantação do projeto, uma área destinada aos cultivos de subsistência, os quais poderiam ser produzidos apenas em locais que não se prestavam à irrigação, conhecidos como "botafora".

Além disso, a produção total dos colonos, incluindo-se a do consumo próprio, deveria ser colocada na Cooperativa dos irrigantes que só posteriormente destinaria a cada familia a cota referente à manutencão familiar. Esta situação acabou por gerar uma crescente insatisfação entre os colonos irrigantes levando-os, em alguns casos, a desistirem de seus lotes agricolas ainda durante os primeiros anos de sua instalação no perimetro.

Atualmente pode-se observar a existência de uma relativa autonomia na organização das unidades produtivas quanto ao comportamento dos produtores na instância mais imediata do processo produtivo, isto ć, quanto à decisão da área e do sistema a ser cultivado, assim como pela opção de comercializar, através da cooperativa. Constatamos ainda que os colonos podem destinar $20 \%$ dos seus lotes para o auto-consumo familiar (arroz, feijão, milho), além de poderem criar duas vacas em módia, para a produção de leite, também voltado para o cultivo próprio. 
No que diz respeito à composição da produção comercializada, os dados obtidos em São Gonçalo revelam uma situação também diversa daquela que foi prevista no planejamento oficial. A pauta de produtos cujo plantio foi registrado no PISG se refere, fundamentalmente, àqueles tidos como tradicionais: arroz, banana, coco. Dentre as culturas de alto valor comercial, apontadas como necessárias à viabilização econômica da irrigação no nordeste, somente o tomate vem conseguindo se colocar entre os principais produtos. As experiências com frutas e hortaliças não conseguiram êxito, aparecendo apenas o melão e a melancia, porém com baixa expressividade.

\section{A CAMISG: DA CRIAÇÃO À SITUAÇÃO ATUAL}

O surgimento da Cooperativa agrícola Mista dos Irrigantes de São Gonçalo (CAMISG), em setembro de 1973, pouco tempo após a implantação do projeto irrigado faz com que as suas trajetórias se confundam, formando um mesmo conjunto de informações. A exemplo do que aconteceu com o perimetro, a criação da Cooperativa também se fez sem a efetiva participação dos colonos irrigantes. A própria decisão de se criar uma cooperativa não partiu dos produtores que aliás, não tinham qualquer experiência anterior com as práticas associativistas. Nesse sentido, muito mais do que uma ação espontânea, por parte dos produtores, a associação à cooperativa assumiu um caráter compulsório, passando a ser uma das exigências do DNOCS aos produtores que fossem se instalando no perímetro.

Nesse contexto de obrigatoriedade, aos poucos foi se gerando, entre os colonos irrigantes, um sentimento de descontentamento e de insatisfação que, por sua vez, acabou por provocar a reprodução, no interior do perimetro, de mecanismos de comercialização semelhantes àqueles que caracterizavam a prática anterior de parcela importante desses produtores, quando ainda produziam em áreas de sequeiro e eram subordinados aos proprietários de terra.

Não obstante as proibições existentes, por parte do DNOCS, alguns colonos passaram a comercializar sua produção com os "atravessadores" locais, representados, basicamente, por comerciantes 
locais de insumos modernos. Progressivamente a situação foi se agravando. Tanto é assim que, no início dos anos $80 \mathrm{em}$ meio a problemas financeiros decorrentes da diminuição de recursos para a manutenção do perímetro e à crescentc insatisfação por parte dos colonos, o DNOCS resolveu decretar o inicio do período de auto-gestão administrativa da CAMISG. É nesse sentido que, no inicio da década de 1980, a cooperativa foi desvinculada do DNOCS, passando o scu gerenciamento a ser feito através de uma diretoria eleita c composta apenas por colonos, e com autonomia para definir as suas diretrizes de atuação e de funcionamento.

Embora a partir do ano de 1982, a CAMISG tenha, de fato passado a ser dirigida pelos próprios colonos, não se registraram nos primeiros anos de auto-gestão, mudanças significativas na postura dos colonos frente àquela entidade, até pela situação deficitária, em que a receberam c, mesmo, pela falta de familiaridade dos produtores com a sua mecânica de funcionamento.

Existem aliás, muitas queixas, por parte dos colonos com relação às gestões das duas primeiras dirctorias eleitas, a partir do início do período de auto-gestão, em termos de desempenho administrativo. Entre os entrevistados, as mais mencionadas foram: ineficiência distanciamento em relação aos sćcios e desmandos administrativos, como por exemplo, desvios de recursos por parte dos dirigentes.

Em virtude dessas circunstâncias, a posição dos produtores frente à cooperativa pouco se modificou. A única alteração de importância que pudemos detectar no periodo foi o fato de que os colonos passaram a se sentir, efetivamente, donos de sua produção, podendo escolher como e com quem comercializá-la. Em meio a tais insatisfações, a possibilidade de escolher com quem comercializar a produção levou importante parcela dos produtores a optar pelos intermediários e não pela cooperativa, que chegou a operar, em alguns periodos, apenas com cerca de trinta associados. Consequentemente, foram se criando novos vínculos de dependência dos colonos face aos atravessadores locais que, como já dissemos anteriormente, eram representados, naquele momento, pelos comerciantes de insumos modernos. 
Até bem pouco tempo atrás, era esse o quadro caracteristico da comercialização do PISG. Tanto foi assim, que mesmo $\mathrm{em}$ periodos recentes pudemos constatar a evidência desse fato. Observamos, inclusive, que a intermediação comercial parecia estar se institucionalizando no âmbito do projeto. Registramos, a propósito, a presença de um comerciante de insumos agrícolas, que havia ocupado uma casa de farinha de propriedade do DNOCS (então desativada), na qual instalara o seu "escritório" de comercialização. Era neste local, dentro do perímetro, que os irrigantes podiam adquirir fertilizantes, defensivos, enfim, os insumos necessários à produção, ao mesmo tempo em que a repassavam para aquele intermediário. Embora a gerência do perimetro já houvesse exigido a desocupação do imóvel, medidas concretas, nesse sentido, ainda não haviam sido tomadas. Aliás, nem mesmo a terceira diretoria regional do DNOCS, à qual o perímetro é jurisdicionado, havia sido informada sobre o acontecimento. Este atravessador tinha respaldo tanto de políticos locais, como dos próprios colonos.

É nesse contexto que outros estudos realizados no perímetro de São Gonçalo, no periodo ora considerado, apontaram como tendência a ser seguida naquela área o "fortalecimento de uma estrutura tradicional de comercialização". Ocorre que esta tendência não veio a se confirmar, tendo em vista que importantes alterações foram se verificando, ao longo do tempo, na área do perimetro e a realidade há pouco descrita, se encontra hoje bastante modificada.

A mudança mais significativa foi a reestruturação da própria cooperativa, que passou a atuar em novas bases administrativas e passou a assumir funções mais amplas do que a de simples agente de comercialização de produtos irrigados. Hoje, a cooperativa além de ser 0 principal agente de comercialização na área de perímetro - contando $\grave{a}$ época da pesquisa de campo em seu quadro social com 400 associados passou a exercer funçõos de escoamento da produção, compra de insumos em melhores condições e, em especial, a de fornecedora do crédito bancário e de outros elementos de modemização, cujo acesso para os irrigantes individualmente tomar-se-ía muito mais dificil. Desse modo, a pesquisa de campo realizada entre os produtores de São Gonçalo, (jan/1993), revelou que a reestruturação da cooperativa é um fato recente que só agora começa 
a se manifestar a cujas possibilidades de fortalecinicino sa ampliam a pattir da mudança de atitude dos produtores e do seu gma siv cirvolvimento frevto àquela entidade.

Reconhecendo a existência do precesco dis reestruturạ in CAMISG pode-se destacar três aspectos básicus que o evidencia nos primciros anos dessa década:

(1) O processo de reorganização interna da cooperativa iniciads a partir do ano de 1990. tem-sc feito acompanhar da crescente importância do crédito oficial no âmbito do projeto. onde $81.9 \%$ dos entrevistados ( 83 colonos) utilizavam crédito agrícola (custeio e investimento).

(2) Em decorrência do primeiro aspecto, a mecanização no perimetro está associada à utilização de financiamentos oriundos do sistema bancário (de custeio e de investimento):

(3) O terceiro c último aspecto a destacar é o fato de que a comcrcialização não está mais sujeita aos agentes de intermediação que, atualimente. no purimetro. são figuras secundárias. $84.8 \%$ dos colonos entrevistados ( 73 colnnos) comercializam sua produção através da cooperativa. $10.5 "$ " ( $(\%$,olonos) através dos particulares e $4.6 \%$ (4 colonos) itravis do , whas a! i iomas.

Irtı 'i's: ch cridências surgen portanto as indagações: Quc falores i. Como fi sivil al recstruturaçion? Quais são as perspectivas e as implicaç c chais a midio c longo prazos do processo de reestruturação da coope a sobr o grupo social cis olvido?

Para a n: thor compreensão cio referido processo. fomos buscar espostas a partır rus nossos pri os iiformantes. até mesmo por falta de maiores riferências teóricas sol, u faú. De acordo com os entrevistados

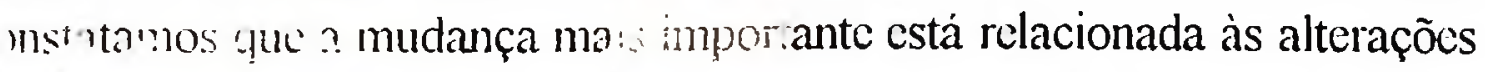

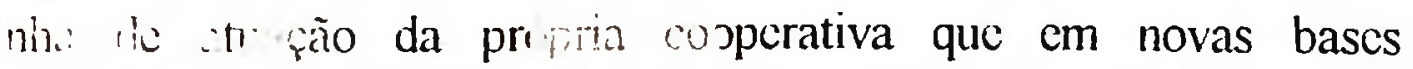
$\therefore .49 ., \ldots$ contrário is dirsturias anteriores, passou a priorizar 11. . . wais amplos que a me losici ialização de produtos irrigados ou o simpl's repasse de crédito baurcino ans seus associartis. A ênfase passou a ser a aterdinento de outris demaitidas que estriessem diretamente 
relacionadas às atividades produtivas e às necessidades mais imediatas do perimetro, tais como: fortalecimento da infraestrutura hídrica do projeto, extensão da rede elétrica aos lotes agrícolas, aumento de estoque de equipamentos e da frota de veículos e, a médio e longo prazo, a introdução de novos cultivos.

É nessa perspectiva que a mais recente atuação da cooperativa tem sido no sentido de promover a elaboração de projetos de desenvolvimento econômico e social junto ao Banco do Nordeste. com vistas à obtenção de recursos da linha de financiamento do Fundo Constitucional de Financiamento do Nordeste (FNE) para concretização desses objetivos. Desse modo, a ampliação das funções da cooperativa fizeram com que a CAMISG passasse a ser vista pelos produtores como uma "verdadeira empresa", conforme expressão usada por um de nossos entrevistados.

Por outro lado, apesar dessas constatações é ainda prematuro considerar que o desempenho favorável da cooperativa seja um atestado de que esta tenha hoje uma estrutura tecnológica e politicamente consolidada ou que venha a ser a solução global para os problemas do perímetro, pelo menos na forma em que se encontra estruturada no momento. A reorganização do processo produtivo em São Gonçalo, a partir da reestruturação da cooperativa é um importante aspecto de um processo mais amplo de transformação social cuja consolidação depende, em grande medida do nivel de organização política dos colonos irrigantes. que ainda é incipiente no perimetro acima. Pudemos inclusive observar que cmbora reconheçam a importância de uma "cooperativa de verdade", não percebem que o seu bom desempenho atual está diretamente relacionado ao apoio. à credibilidade e a participação deles próprios. colonos irrigantes. junto àquela instituição.

Embora essa limitação particular se refira naturalmente ao fato do perímetro ter sido um espaço organizado pelo Estado e, ao controle ideológico que caracterizou os primeiros anos de implantação do projeto. A exemplo do que aconteceu em outros perímetros também implantados. no contexto do governo militar, cuja especificidade era ter sob controle qualquer tentativa de reivindicação por parte dos produtores. 
Existe, porém, um potencial de organização própria dos colonos irrigantes que se evidencia não apenas na consciência dos problemas existentes mas, principalmente, na percepção de que qualquer melhoria para os pequenos agricultores passa pela sua organização e a sua participação em associações de produtores. Por conseguinte, começa a se forjar no perimetro uma consciência quase generalizada da importância das práticas associativistas. Dos 83 colonos entrevistados, $77,1 \%$ responderam que achavam que os pequenos produtores podiam influenciar as políticas agrícolas. Destes que assim responderam, 96,9\% afirmaram que a forma de influenciar as políticas seria organizando-se em cooperativas.

Porém, as tendências a serem seguidas e as implicações futuras do processo de modernização e transformação social em curso, no âmbito do PISG, não são lineares, sendo por isso uma incógnita. Por ora, o que se pode afirmar, com base nas informações disponíveis para os primeiros anos dessa década é que esse é um momento de um processo ainda em andamento que por isso mesmo apresenta transformações parciais, mas que já serve como demonstração de que cabe à cooperativa um papel importante a ser desempenhado e que, além disso, é sempre possível recomeçar.

\section{CONSIDERAÇOES FINAIS}

A experiência da CAMISG nos indica um direcionamento da pequena produção irrigada no sentido de um aprofundamento das relações comerciais. Isto se configura, por um lado, através do aumento da utilização do crédito agrícola e, por outro, através da necessidade de parte cada vez maior da produção se destinar ao mercado. Isto denota um crescente envolvimento dos colonos irrigantes com a lógica modernizante. Esta resposta positiva foi possível no caso de São Gonçalo, através da maior autonomia conquistada pelos irrigantes para definir seus destinos.

A comercialização da produção é atualmente exercida de forma predominante pela CAMISG. Após se deparar, durante os seus primeiros anos de operação, com problemas que iam desde o baixo nivel de associativismo a deficiências administrativas, a Cooperativa começou a se reestruturar a partir da diminuição da interferência do Estado sobre aquela 
entidade, ocorrida em períodos recentes. A mudança de posicionamento dos colonos frente a Cooperativa e o surgimento de iniciativas e lideranças entre os produtores, são aspectos importantes que tambén evidenciam o processo de transformações sociais em curso no Projeto \$ão Gonçalo.

É fundamental não perder de vista o fato de que parcela significativa desses produtores é originária de uma cultura forjada no contexto de uma agricultura de sequeiro, passando a enfrentar inúmeras dificuldades de adaptação à prática da imigação. A agricultura intigada, planejada para desenvolver cultivos comerciais, impóe um outro tipo de racionalidade, que se expressa através de exigências enin matéria de custos financeiros, de incorporação de novas técnicas e de eficiência econômica, com as quais esses produtores não cstavam acoshumados. Seus conhecimentos anteriores sobre irrigação são realmente muito restritos, ou até mesmo inexistentes.

A assimilação dos colonos/irrigantes tende a ser lenta também, em virude das práticas patemalistas camoterítice dos esquemas governamentais, nos primeiros anos de elemento fundamental que não se pode $c$. angiclo das atividades produtivas no ausencia da participação dos colonos em $\mathrm{S}$

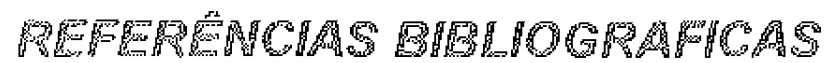

AlMEIDA Jr., Armando F. Rela jeto da CODEVASF. Disserta hepo mine Dutro Federal da Paraiba - Campina 10,1 io. Universida

BND/ETENE. Avaliação do PR! Irrigaçăo. Fortaleza, 1985. (P. ade, $:-8$

BNB. Informaçôes Básicas sobre ATE (Fur... Conshincion? de Financiamento do Nordeste : 1.1992

BNB; DNOCS \& SUDENE. Pes\% sol; \% \%

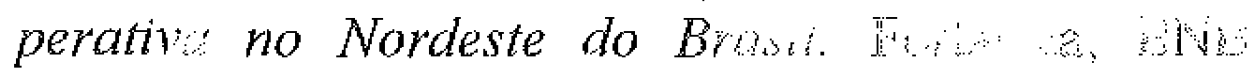
(Estuợ Econômicos e criais, 1 l). 
CAMISG. Projeto de Desenvolvimento Econômico e Social. Perimetro Irrigado de São Gonçalo. 1992.

CARVAlHO, O. de. A Economia Politica do Nordeste (Seca, Irrigação e Desenvolvimento). Rio de Janeiro: Campus; Brasilia: ABID - Associação Brasileira de Irrigação e Drenagem, 1988.

CASTRO, Ana Célia et alii. Evolução Recente e Situação Atual da Agricultura Brasileira. Brasília, BINAGRI, 1979.

CODEVASF. Proposta de Auto-gestão das Cooperativas de Irrigantes. Documento preliminar. Fortaleza, 1983.

CORREA, José B. Emancipação dos Projetos de Irrigação do DNOCS: Fundamentos do Programa. s.1., 1990 (Mimeo.).

COSTA, Antonieta P. Cooperativismo e Estado (O Caso do Projeto São Gonçalo). Dissertação de Mestrado. Vrr versidade Federal da Paraiba - João Pessoa, 1984.

DELGADO, Guilherme da C. Capitalismo Financeiro e Agricultura no Brasil. São Paulo, I cone-Unicamp, 1985.

DNOCS. Normas de Colonização. Marual de Ocupaçấo Es.pacial. Brasilia, 1979.

GRAZIANO DA SILVA, J. (Coord); Angela Kageyama et alii. A Irrigação e a Problemática Fundiária do Nordeste. Campinas, Instituto de Economia: PRONI, 1988.

IICA. Instituto Interamericano de Cooperação para a Agricultura. Comitê Institucional da Familia e da Mulher Rural. A Posição da Mulher em Projetos de Irrigação. Brasilia. CODEVASF, 1980.

KAGEYAMA, Angela et alii. O Novo Padrão Agricola Brasileiro: Do Complexo Rural aos Complexos Agroindustriais. Campinas, Unicamp, 1987. Mimeo. 
KAGEYAMA, Angela et alii, Modernização, Produtividade e Emprego na Agricultura: Uma Análise Regional. Tese de Doutorado, Universidade Estadual de Campinas, 1985.

MARA/SENIR. Atuação da CODEVASF e do DNOCS no Desenvolvimento da Irrigação no Nordeste. Brasília, 1990. (Versão preliminar).

MARTINE, George. "A Trajetória da Modernização Agrícola: A Quem Beneficia?" In: Lua Nova, São Paulo, CEDEC, $\mathrm{n}^{\circ}-$.23. 1991. p. 07-37.

MARTINE, George \& BESKOW, Paulo R. "O Modelo, os Instrumentos e as Transformações na Estrutura de Produção Agrícola", In: MARTINE, George \& GARCIA, Ronaldo (org.). Os Impactos Sociais da Modernização Agricola. São Paulo: Caetés/Hucitec, 1987. p. 19-39.

MINTER/DNOCS. DNOCS - Pensamento e Diretrizes. Fortaleza, 1984. (Edição comemorativa do $75^{\circ}$ - aniversário do DNOCS).

MIRANDA, Érico. Tomate Industrial: Gênese e Desenvolvimento da Produção Integrada nas Áreas Irrigadas de Petrolina e Juazeiro. Dissertação de Mestrado. Universidade Federal da Paraiba. Campina Grande, 1991.

MOTA, Dalva M. Os Camponeses e Busca da Autonomia Possivel. Dissertação de Mestrado. Universidade Federal da Paraíba - Campina Grande, 1990.

NIEPCE. O DNOCS e o Novo Nordeste: Uma Perspectiva Histórica (1909-1984). Fortaleza, DNOCS, 1984, 2v.

SAMPAIO, Yoni et alii. Politica Agrícola no Nordeste: Intenções e Resultados. Brasília, BINAGRI, 1979.

SUDENE. Diagnóstico do Desempenho do Programa de Irrigação do Nordeste. Recife, Assessoria Rural, 1980. 
SUDENE. Relatório Sintético sobre Programas de Irrigação do Nordeste. Recife, 1980 (Vários volumes).

VIEIRA; Vicente de Paulo P. B. Sistema de Exploração do Perimetro Irrigado no Nordeste Brasileiro: Aspectos Administrativos, Técnicos e Sócio-Econômicos. Fortaleza, DNOCS, 1979.

VILELA, Sérgio. Águas Públicas/Riquezas Privadas (A Poltica de Irrigação para o Vale do São Francisco: Bebedouro e Nilo Coelho). Dissertação de Mestrado. Universidade Federal da Paraiba - Campina Grande, 1991. 